MONETARY POLICY AND POTENTIAL OUTPUT UNCERTAINTY

\title{
A QUANTITATIVE
} ASSESSMENT 


\section{MONETARY POLICY AND POTENTIAL OUTPUT UNCERTAINTY} A QUANTITATIVE ASSESSMENT '

by Simona Delle Chiaie ${ }^{2}$

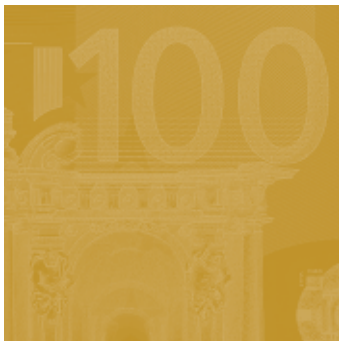

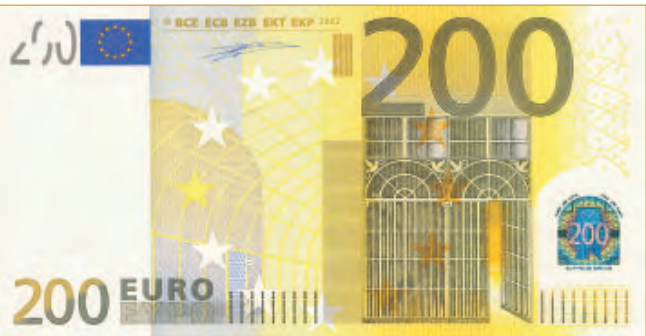

In 2009 all ECB publications feature a motif taken from the $€ 200$ banknote.
This paper can be downloaded without charge from http://www.ecb.europa.eu or from the Social Science Research Network electronic library at http://ssrn.com/abstract_id $=1520350$.

I I am specially grateful to Francesco Lippi, Fabio Canova, Antonio Guarino, Stefano Neri, Lucio Sarno, Carl Walsh for helpful suggestions. I also thank seminar participants at the Oesterreichische Nationalbank and the Sveriges Riksbank for useful comments. Of course I take full responsibility for any errors or omissions. The views expressed in this paper are those of the author and do not necessarily reflect those of the European Central Bank or Oesterreichische National Bank. Part of this work was done while the author was visiting the University of Pompeu Fabra, whose kind hospitality is gratefully acknowledged. 
(C) European Central Bank, 2009

Address

Kaiserstrasse 29

60311 Frankfurt am Main, Germany

Postal address

Postfach 160319

60066 Frankfurt am Main, Germany

Telephone

+496913440

Website

http://www.ecb.europa.eu

\section{Fax}

+496913446000

All rights reserved.

Any reproduction publication and reprint in the form of a different publication, whether printed or produced electronically, in whole or in part, is permitted only with the explicit written authorisation of the ECB or the author(s).

The views expressed in this paper do not necessarily reflect those of the European Central Bank

The statement of purpose for the ECB Working Paper Series is available from the ECB website, http://www.ecb.europa. eu/pub/scientific/wps/date/html/index. en.html

ISSN 1725-2806 (online) 


\section{CONTENTS}

Abstract

Non-technical summary

1 Introduction

2 The model economy

3 Estimation

3.1 Estimation results

4 Potential output uncertainty and monetary policy

5 Robustness

5.1 Changes in priors

5.2 Alternative timing for indicators

6 Concluding remarks

Appendix

References

Tables and figures

European Central Bank Working Paper Series 


\begin{abstract}
I estimate a dynamic stochastic general equilibrium model where the policymaker and the private sector have imperfect knowledge about potential output. The estimation of the structural parameters and of the monetary authorities'objectives is key to assess the quantitative relevance of the imperfect information problem and to evaluate the robustness of previous exercises based on calibration. The estimated model also allows me to revisit the Orphanides $(2001,2003)$ findings that the central bank can makes large and persistent mistakes to estimate potential output in response to productivity and cost shocks. I find that when real unit labor cost is used as a monetary policy indicator, the potential output uncertainty has quantitatively negligible consequences on policy behaviour and inflation dynamics.
\end{abstract}

Keywords: Monetary policy, potential output uncertainty, indicator variables, real unit labor cost.

JEL Classification: E4, E5 


\section{Non-technical summary}

The inability of central banks to observe potential output in real-time has received attention as having important implications for the conduct of monetary policy. For instance, several authors have highlighted how the significant misperception of potential output, following the productivity slowdown of the early 1970s, may have contributed to the rise of U.S. inflation. In this paper, I revisit the issue by estimating a dynamic stochastic general equilibrium model where the policymaker and the private sector have imperfect knowledge about potential output. Using the model structural estimates, I show how the quantitative implications of potential output uncertainty crucially hinge on the policymaker's information set. This is done by comparing the case in which the central bank uses noisy measures of output, inflation and real unit labor cost to estimate the potential output level with the counterfactual situation in which the real unit labor cost indicator is removed from the central bank's vector of observables. An interesting contrast emerges between the scenarios. The results show that the central bank makes large and persistent errors in forecasting the output gap, when output and inflation are the only indicators used to estimate the potential output. In particular, following a unitary decrease in potential output, the output gap is perceived as negative for about 7 quarters, while its true value is actually positive. The forecast error leads optimal policy to deviate from its benchmark value of full information causing a persistent inflation hike (for about 12 quarters) in comparison with the complete information case. Instead, when monetary policy makes use of the real unit labor cost indicator (in addition to output and inflation data), then potential output uncertainty turns out to have quantitatively negligible consequences on inflation dynamics and on the policy makers' welfare. 


\section{Introduction}

Central banks' inability to observe the potential output in real-time has received attention as having important implications for the conduct of monetary policy. For example, Orphanides (2001, 2003), Lansing (2000), Cukierman and Lippi (2005) have highlighted how the significant misperception of potential output, following the productivity slowdown of the early 1970s, may have contributed to the rise of U.S. inflation.

Although these previous studies shed light on the economic mechanisms by which the imprecise measurement of potential output might affect the policy behavior and thus, the dynamics of inflation, they have been conducted mainly by means of calibrations (e.g. Ehrmann and Smets (2003), Cukierman and Lippi (2005)).

This approach turns out to be not exhaustive since quantitative findings depend on the particular set of calibrated parameter values. For instance, the size and persistence of the potential output forecast errors and, therefore to what extent policy deviates from the ideal full information benchmark depend on the relative variance of potential output and cost-push shocks. Common welfare measures, such as the central bank expected losses and its ability to control inflation, the output gap and the interest rate adjustments also depend on the covariance matrix of the shocks as well as weights attached to the central bank's objective function.

This paper contributes to this recent quantitative literature on the monetary policy consequences of the imperfect information about potential output along several dimensions.

First, this paper estimates a dynamic stochastic general equilibrium model (DSGE) which explicitly accounts for the incomplete information about the state of the economy by means of Bayesian techniques. The estimation of the structural parameters and of the monetary authorities' objectives allows to appraise empirically the quantitative importance of the potential output uncertainty and also, provides a benchmark for evaluating the robustness of previous calibrations.

Second, this paper illustrates that the quantitative implications of the potential output uncertainty crucially hinge on the information set available to the policymaker. This is done by comparing the case in which the central bank uses noisy measures of output, inflation and real unit labor cost to estimate the potential output level with the counterfactual situation in which the real unit labor cost indicator is removed from the central bank's vector of observables.

An interesting contrast emerges between the two potential output estimates. The results reveal that the central bank makes a large and persistent error in forecasting the output gap, when output and inflation are the only observables that are used to estimate the potential output. In particular, following a unitary decrease in potential output, the output gap is perceived for more than 7 quarters as negative whereas it is actually positive. The forecast error leads optimal policy to deviate from its benchmark value of full information causing a persistent inflation increase (about 12 quarters) in comparison with the temporary effect under complete information. When the real unit labor cost 
indicator is instead available to the central bank, the forecast error turns out to be quantitatively negligible. As a consequence, the optimal policy does not deviate substantially from its benchmark of full information. In this case potential output uncertainty does not produce quantitative noticeable consequences on inflation dynamics.

The results in this paper are in line with the findings of Lippi and Neri (2007) for the euro area. Using a small DSGE model estimated through likelihood-based methods and under the assumption of imperfect information, the authors analyse the information role of the unit labor cost and monetary aggregates. They show that the former contains useful information on potential output that help to stabilize the output gap target.

The paper proceeds as follows. Next section presents the model. Section 3 illustrates the estimation details and comments the results. Section 4 analyses the quantitative effects of signal extraction errors arising from potential output uncertainty and, along this dimension, the usefulness of real unit labor cost as a monetary policy indicator. Section 5 concludes.

\section{The model economy}

The model, taken from Ehrmann and Smets (2003), consists of the following equations:

$$
\begin{aligned}
y_{t} & =\delta y_{t-1}+(1-\delta) y_{t+1 \mid t}-\sigma\left(i_{t}-\pi_{t+1 \mid t}\right)+u_{y, t} \\
\pi_{t} & =\alpha \pi_{t-1}+(1-\alpha) \pi_{t+1 \mid t}+\kappa\left(y_{t}-\bar{y}_{t}\right)+u_{\pi, t}, \\
\bar{y}_{t} & =\rho \bar{y}_{t-1}+u_{\bar{y}, t} .
\end{aligned}
$$

where $\pi_{t}, y_{t}, \bar{y}_{t}$, and $i_{t}$ denote, respectively, inflation, output, potential output and the nominal short term interest rate. The preference shock $u_{y, t}$, the cost - push shock $u_{\pi, t}$ and the potential output shock $u_{\bar{y}, t}$ are i.i.d. innovations with zero mean and covariance matrix $\Sigma_{u}^{2}$.

Since in this specification the dynamics of output and inflation depend on both lagged and expected future values, the model is considered as a hybrid version of more traditional backward looking models such as in Svensson (1997a, 1997b) and purely forward looking models such as in Rotemberg and Woodford (1997) and Clarida et al. (1999).

The central bank chooses a path for the short-term interest rate minimizing the intertemporal loss function (4) which is over three policy goals: inflation, output gap and the change in the short term nominal interest rate.

$$
E_{t} \sum_{\tau=0}^{\infty} \beta^{\tau}\left[\pi_{t+\tau}^{2}+\lambda\left(y_{t+\tau}-\bar{y}_{t+\tau}\right)^{2}+\nu\left(i_{t+\tau}-i_{t+\tau-1}\right)^{2} \mid I_{t}\right]
$$

The relative weights $\lambda$ and $\nu$ synthesize the preferences of the policymaker over the related policy targets. 
The central bank and the other agents infer the state of the economy on the basis of three indicators. Such indicators provide contemporaneous but noisy measures of output, inflation and real unit labor cost $\left(y_{t}^{\circ}, \pi_{t}^{\circ}, c_{t}^{\circ}\right.$, respectively) and are represented by the following vector of measurables:

$$
\begin{aligned}
y_{t}^{\circ} & =y_{t}+v_{y, t}, \\
\pi_{t}^{\circ} & =\pi_{t}+v_{\pi, t}, \\
c_{t}^{\circ} & =c_{t}+v_{c, t} .
\end{aligned}
$$

The measurement errors in the vector $v$ are assumed to be i.i.d. with covariance matrix $\Sigma_{v}^{2}$ and they are uncorrelated with the vector of innovations $u$. According to the New Keynesian paradigm, the firms' inability to adjust prices optimally every period creates the existence of a wedge between output and its natural level (output gap). As shown, among others, by Rotemberg and Woodford (1997), the output gap is proportional to deviations of real marginal cost from steady state. Hence, a measure of real marginal cost can be used to approximate (up to a scalar factor) the true, or model-based, output gap. In line with this result and, following Lippi and Neri (2007), I extent the model assuming that the actual value of real unit labor cost $c_{t}$ is given by:

$$
c_{t}=\mu\left(y_{t}-\bar{y}_{t}\right)
$$

Agents and the policymaker in the economy have symmetric information both on the model parameters, $\Omega \equiv\left[\alpha, \beta, \delta, \kappa, \lambda, \mu, \nu, \rho, \sigma, \Sigma_{u}^{2}, \Sigma_{v}^{2}\right]$ and on the whole history of the observables, therefore the information set $I_{t}$ at period $t$ is represented by $I_{t} \equiv\left\{Z_{\tau}, \tau \leq t ; \Omega\right\}$.

Restricting the attention to the case in which central bank operates under discretion, following Svensson and Woodford (2003) the equilibrium (i.e. Markov perfect) under discretion is characterized by the optimal policy rule being a linear function of the current estimate of the predetermined variables. The equilibrium law of motion of the state, forward-looking and indicator variables as well as the optimal predictor of the state vector, are given by:

$$
\begin{aligned}
i_{t} & =F X_{t \mid t}, \\
X_{t+1} & =H X_{t}+J X_{t \mid t}+C_{u} u_{t+1}, \\
Z_{t} & =L X_{t}+M X_{t \mid t}+v_{t}, \\
x_{t} & =G X_{t \mid t}+G^{1}\left(X_{t}-X_{t \mid t}\right), \\
X_{t \mid t} & =X_{t \mid t-1}+K\left[L\left(X_{t}-X_{t \mid t-1}\right)+v_{t}\right] .
\end{aligned}
$$


The matrices $F, G, G^{1}, H, J, K, L$ and $M$ are defined in Svensson and Woodford (2003) and depend on the parameters in $\Omega$, whereas $X_{t}^{\prime} \equiv\left[\begin{array}{lllll}y_{t-1} & \pi_{t-1} & \bar{y}_{t} & u_{y, t} & u_{\pi, t} \\ i_{t-1}\end{array}\right], x_{t}^{\prime} \equiv\left[y_{t}\right.$ $\left.\pi_{t}\right], u_{t}^{\prime} \equiv\left[\begin{array}{lll}u_{\pi, t} & u_{y, t} & u_{\bar{y}, t}\end{array}\right]$ and $Z_{t}^{\prime} \equiv\left[\begin{array}{lll}y_{t}^{\circ} & \pi_{t}^{\circ} & c_{t}{ }^{\circ}\end{array}\right]$ stand for, respectively, the predetermined state variables, the forward-looking variables, the structural shocks, the observables and, finally, $i_{t}$ is the central bank's policy instrument.

As in recent papers by Schorfheide (2001), Smets and Wouters (2003) and FernándezVillaverde and Rubio-Ramírez (2004), the model is estimated using Bayesian methods. The next section focuses on the estimation methodology and comments the empirical findings.

\section{Estimation}

This section illustrates the estimation of the model by means of Bayesian techniques. The data $f_{t}$ used in the estimation are the short-term nominal interest rate and the three observables of the theoretical model: output, inflation and real unit labor cost. ${ }^{1}$ The measurement equation is given by:

$$
f_{t}=C S_{t}+e_{2, t},
$$

where $S_{t} \equiv\left[\begin{array}{ll}X_{t} & X_{t \mid t-1}\end{array}\right]^{\prime}$ represents the state variables of system (10-13) and $e_{2, t}$ :

$$
e_{2, t} \equiv D v_{t}+\xi_{t},
$$

is the vector of measurement errors which is inclusive of $\xi_{t} \equiv\left[\begin{array}{llll}0 & 0 & 0 & \xi_{i, t}\end{array}\right]^{\prime}$. Since the measurement errors already appear in the theoretical model (the vector $v_{t}$ ), the element in $\xi_{t}$ associated with the observables are assumed to be identically zero. The measurement error $\xi_{i, t}$ on the interest rate is instead needed in order to avoid a stochastic singularity problem. The measurement equation (14) and the law of motion of the states $S_{t}$ represent a state space system to which the Kalman filter as in Sargent (1989) can be applied.

The posterior densities of the model parameters are then computed combining the likelihood function with diffuse prior distributions. The analytical derivation of the likelihood function as well as technical details concerning prior distributions are described in the appendix.

\footnotetext{
1 This analysis uses U.S. data. Output is measured by the log of seasonally-adjusted real gross domestic product in chained 2000 dollars, the inflation rate is provided by the log of the quaterly changes in the seasonally adjusted GDP implicit price deflator, real unit labor cost is represented by the series of the $\log$ of labor income share in the non-farm business sector and finally, the three-month U.S. Treasury bill rate provides the measure of the nominal interest rate (expressed in percentages per quarter). The data are quarterly and run from 1960:1 through 2005:4. Real variables are linearly detrended before the estimation whereas nominal variables are demeaned.
} 


\subsection{Estimation results}

The analysis produces reasonable posterior distributions for the model parameters. Data are informative in the sense that posterior distributions are more concentrated and many of them, are shifted relative to the priors. Table 1 reports relevant statistics of prior distributions, the estimated posterior medians and $95 \%$ confidence intervals of posterior distributions. $^{2}$

Focusing on the posterior distribution of the backward-looking component of the New-Keynesian Phillips curve, one observes that the posterior distribution has a small dispersion with a range that goes from 0.43 to 0.53 . These findings imply a degree of inflation inertia greater than in Galí and Gertler (1999) supporting the view that both backward looking and forward looking behavior are important in shaping the U.S. inflation dynamics. The posterior distribution of the Phillips curve slope suggests a significant effect of real activity on inflation. The posterior median is 0.06 and it is consistent to the estimates obtained by Galí and Gertler (1999) and Galí, Gertler and Lopez - Salido (2005) using GMM .

Regarding the structural parameters of the aggregate demand equation, the estimation suggests that both backward and forward looking components are significant in explaining output dynamics. The posterior mean of the elasticity of output to the real interest rate is 0.15 and it is consistent with previous results found in the Real Business Cycle literature. The analysis also delivers plausible estimates for the parameters describing the preferences of the monetary authority. The posterior mean of the weight attached to the output gap $\lambda$ is 0.51 suggesting that the policymaker looks out for the deviation of output from its natural level and it is at odds with the estimates of Dennis (2006) and Lippi and Neri (2007) for the euro area. The estimate of $\nu(0.62)$ provides evidence of a substantial degree of interest rate smoothing. The estimates of the structural shocks $\left(\sigma_{u}\right)$ show that demand and cost-push shocks have the largest standard deviation. The k-step ahead forecast error variance decomposition of Table 2 indicates that cost-push shocks are the main source of fluctuations for inflation and they also explain a substantial part of the interest rate volatility at all horizons. Demand shocks are the main source of output fluctuations, even though for longer horizons the contributions of potential output and cost-push shocks increase. Demand shocks also explain more than one half of the variance of the interest rate and large part of the output gap volatility. The estimates also show that the measurement error concerning real unit labor cost is rather small. The measurement errors of output and inflation are higher (0.20 and 0.16 , respectively), even

\footnotetext{
${ }^{2}$ Posterior distributions are based on 50000 draws obtained through the Metropolis-Hastings sampling algorithm. The variance of the innovation in the $\mathrm{MH}$ has been set in order to get an acceptance rate of $30 \%$. The cumulative sum of draws statistic (CUMSUM) is used to check for convergence. This is achieved after 30000 iterations.

${ }^{3}$ In a first version of this paper, the model was estimated by excluding the unit labor cost indicator. The estimation results showed that the Phillips curve slope estimate was close to zero and moreover, the standard deviations of the cost-push shock and the measurement errors were very high. These findings suggested to re-estimate the model taking into account a better proxy for the output gap rather than the detrended GDP (e.g. Galí and Gertler (1999)).
} 
if the variance decomposition analysis of Table 2 indicates that they have a marginal role in explaining the variables' fluctuations.

\section{Potential Output Uncertainty and Monetary Pol- icy}

Using the estimates of the structural parameters and of the monetary authority's objectives, this section analyses the quantitative relevance of the imperfect information about potential output for monetary policy. The analysis is conducted examining the dynamic responses of some variables of interest to several shocks and in particular, comparing outcomes of three different cases.

The first case is one with complete information (CI) which implies that all agents in the economy observe potential output and therefore, they can perfectly derive the nature of the shocks that hit the economy. In the second case, the central bank and the private sector are subject to incomplete information (II) about potential output. This implies that agents do not observe potential output directly and they have to infer the state of the economy on the basis of three noisy indicators: output, inflation and real unit labor cost. Finally, in the third case, agents are still subject to incomplete information about potential output but the real unit labor cost indicator is removed from the vector of observables. Starting with the case in which the real unit labor cost indicator is not available to the agents in the economy, Figure 1 presents the responses of the actual and perceived output gap, the output gap forecast error, the inflation and the nominal interest rate following a unitary decrease in potential output ${ }^{4}$.

Two main results emerge. First, the error in forecasting the output gap is large and persistent. For about 7 quarters, the central bank estimates the output gap as negative while this is actually positive. The origins of such error stem from the fact that the central bank just observes a raise in price and a fall in output but, under imperfect information, does not perfectly recognize if those effects are caused by a negative potential output shock or a positive cost-push shock (or a combination of both). As a result, it is forced to assign some probability to the fact that this is actually a positive cost-push shock which causes an over-prediction of the potential output. Second, the forecast error leads the optimal interest rate to deviate greatly from its benchmark value under perfect information causing a persistent raise in inflation (about 12 quarters) in comparison with the temporary effect under complete information.

Figure 2 analyses the responses of the variables of interest following a positive cost push shock. As a consequence of the signal extraction problem, the central bank assigns some probability that a negative potential output shock is hitting the economy, causing an under - prediction of the potential output. However, since temporary cost-push shocks are estimated to be more volatile than those to potential output, the magnitude of the forecast

\footnotetext{
4 The impulse responses of this section are based on the posterior median.
} 
error is small and the optimal policy is not significantly different from its benchmark of full information.

Figure 3 and 4 illustrate the responses of the variables of interest when the central bank can infer the level of potential output based on output, inflation as well as real unit labor cost. The key results of these two figures are that, in both cases, when the real unit labor cost indicator is available to the agents, the errors in forecasting the output gap are quantitatively negligible. As a consequence, the optimal monetary policy rule as well as the inflation dynamics almost completely overlap their benchmarks of complete information.

The finding that the forecast error is very small when real unit labor cost is used to estimate the output gap suggests that this indicator contains useful information on potential output. At the same time, this result confirms the objection raised by Galí and Gertler (1999), Sbordone (2002), Galí and Gertler and Lopez-Salido (2005) about using the detrended GDP (the deviations of log GDP from a smooth trend) as a proxy for the output gap in empirical applications.

Figure 5 presents an informal assessment of this point based on the patterns of crosscorrelations between two alternative output gap estimates and the actual inflation. The red line in the figure corresponds to the output gap estimate obtained using both the detrended GDP and real unit labor cost while the dotted line corresponds to the counterfactual estimate obtained by removing the unit labor cost indicator from the central bank's vector of observables. A comparison of these two alternative measures of the output gap with actual inflation (solid line) clearly indicates that the output gap series estimated using real unit labor cost presents an higher correlation with actual inflation even though both are positive and statistically significant (0.60 and 0.42 , respectively).

Finally, I study the usefulness of unit labor cost indicator through the effects it produces on some welfare measures. Once again, I analyse how economic performance is affected by the removal of such indicator from the vector of observables. Table 3 reports the standard deviation of target variables (output gap, inflation and interest rate changes) and central bank expected losses. The second column considers the case in which all indicators are available to the central bank. The third one instead shows the values of the standard deviations in the case in which unit labor costs are eliminated from the central bank's information set. This exercise shows that expected losses increase when that indicator is removed from the vector of observables. This effect is mainly due to the raise of the standard deviation of the output gap. On the contrary, the volatility of the interest rate changes declines marginally. This last result could be due to the fact that when unit labor costs are removed from the information set, the greater uncertainty concerning the estimate of potential output causes a reduction in monetary policy activism. 


\section{Robustness}

\subsection{Changes in priors}

An important result of the previous section is that following a potential output shock the output gap forecast error is quantitatively negligible when real unit labor cost is included in the central bank's vector of observables. Equation (13) provides the optimal predictor of the state vector using the Kalman filter. As discussed in Svensson and Woodford (2003), the Kalman gain matrix $K$ is given by:

$$
K=P L^{\prime}\left(L P L^{\prime}+\Sigma_{v}^{2}\right)^{-1}
$$

where the matrix $P \equiv \operatorname{Cov}\left[X_{t}-X_{t \mid t-1}\right]$ is the covariance matrix for the prediction errors $\left(X_{t}-X_{t \mid t-1}\right)$ and fulfills:

$$
P=H\left[P-P L^{\prime}\left(L P L^{\prime}+\Sigma_{v}^{2}\right)^{-1} L P\right] H^{\prime}+\Sigma_{u}^{2} .
$$

The Kalman gain matrix $K$ provides the optimal weights on the vector of observable variables. Namely, row $j$ of $K$ gives the optimal weights in updating of element $j$ of $X_{t}$. Column $l$ of $K$ gives the weights a particular observable variable $Z_{l t}$ receives in updating the elements of $X_{t}$. Note that equations (16) and (17) imply that the elements of the Kalman gain matrix $K$ depend upon the degree of noise in the indicators, i.e. the variance of the measurement errors. Therefore, if the degree of noise of a particular indicator becomes large, the optimal weight on that indicator decreases. Since the estimated degree of noise of real unit labor cost is rather small, the weight that it receives in updating the potential output estimate is high. It is therefore important to understand to what extent this result is sensitive to changes in the prior distribution of the variance of the measurement error. In order to do so, I estimate the model assuming for this parameter a prior distribution with a larger dispersion (i.e. the variance is 1000 times higher). The median of the posterior distribution slightly increases to 0.15 . Despite the raise in the prior range, the posterior standard deviation remains small (0.02).

\subsection{Alternative timing for indicators}

Because information on real variables is usually released with a quarter lag, this section studies the sensitivity of the results to the assumption that both $y_{t}^{o}$ and $c_{t}^{o}$ are related to the previous period value of output and labor cost:

$$
\begin{gathered}
y_{t}^{o}=y_{t-1}+v_{y, t}, \\
c_{t}^{o}=c_{t-1}+v_{c, t} .
\end{gathered}
$$

Figure 6 presents the forecast error output gap, the short-term nominal interest rate and inflation following a unitary decrease in potential output. The figure compares again the 
case of complete information about the state of the economy (solid line) with the case in which potential output is not observed (incomplete information). The dashed line corresponds to the case in which agents infer the state of the economy using three noisy indicators: output, inflation and real unit labor cost. The dotted line corresponds to the counterfactual case obtained by removing real unit labor cost from agents' information set.

When real variables are observed with a quarter lag, the output gap forecast error is, under incomplete information, quite large immediately after the shock. When the central bank's information set only includes output and inflation, the over-estimation of potential output causes monetary policy to deviate substantially from its benchmark of full information, producing a large and persistent raise in inflation. The output gap forecast error instead becomes negligible 3-4 quarters after the shock when unit labor cost indicator is available to the agents. Monetary policy turns out to be too loose only in the first quarter after the shock with a transitory raise in inflation.

\section{Concluding remarks}

This paper contributes to the recent literature that studies the quantitative implications of the imperfect information about potential output for the conduct of monetary policy. For this purpose, a small New Keynesian model which explicitly accounts for the imperfect information problem is estimated by means of Bayesian techniques. Using the estimates of the structural parameters and of the monetary authority's objectives, this paper illustrates that the quantitative implications of potential output uncertainty crucially hinge on the policymaker's information set. When the information set only includes noisy measures of output and inflation, this work corroborates the conclusion by Ehrmann and Smets (2003) that following a potential output shock, the central bank makes a large and persistent error in forecasting the output gap. This error leads the optimal policy to deviate from the benchmark value of full information creating an effect on inflation which is completely absent in the case of perfect information. However, when monetary policy makes use of the real unit labour cost indicator then potential output uncertainty turns out to have quantitatively negligible consequences on inflation dynamics and on the policy makers' welfare.

Altogether, the results of this paper are twofold. First, the real unit labor cost plays an important role for monetary policy. Such indicator provides information about potential output and it strongly improves the central bank's ability in making stabilization policy more effective. Second, this paper contributes to the recent debate on bad policy as opposed to bad luck to explain the so-called Great Inflation. Since the potential output mismeasurement is quantitatively negligible when the policymaker uses efficiently all the information available, the potential output misperception errors could not, with the benefit of hindsight, account for the high inflation episodes of the 1970s.

The relevance of these findings suggests that some working assumptions are worth further analyses. First, it is important to understand to what extent the results depend 
on the linear-quadratic framework used. In this context, uncertainty and imperfect information do not influence the optimal monetary policy because it is characterized by certainty equivalence. Second, the small DSGE model used in this paper is very simple and therefore potentially misspecified. Integrating capital accumulation, sticky wages and capital adjustment costs in the analysis as in the current generation of DSGE models would be a highly useful undertaking.

\section{Appendix}

\section{The Likelihood Function}

This appendix illustrates the main steps for the computation of the likelihood function using the Kalman filter as in Sargent (1989).

First, the solution of the model is transformed into a state space form. Hence from the system (9-13), I derive the law of motion of the unobserved states and a measurement equation that relates the elements of the states vector to the observables.

Using (13) and (10) I get:

$$
X_{t+1}=(H+J K L) X_{t}+J(I-K L) X_{t \mid t-1}+J K v_{t}+C_{u} u_{t+1},
$$

taking expectations and using (13) I obtain:

$$
X_{t+1 \mid t}=(H+J)(I-K L) X_{t \mid t-1}+(H+J) K L X_{t}+(H+J) K v_{t} .
$$

I can rewrite (20) and (21) as follows

$$
S_{t+1}=A S_{t}+B e_{1, t+1}
$$

by defining $S_{t+1} \equiv\left[\begin{array}{c}X_{t+1} \\ X_{t+1 \mid t}\end{array}\right]$

$$
A=\left[\begin{array}{cc}
(H+J K L) & J(I-K L) \\
(H+J) K L & (H+J)(I-K L)
\end{array}\right], \quad B=\left[\begin{array}{cc}
C_{u} & J K \\
0 & (H+J) K
\end{array}\right]
$$

and

$$
e_{1, t+1}=\left[\begin{array}{c}
u_{t+1} \\
v_{t}
\end{array}\right]
$$


In the same way, substituting (13) into (11) and (9) I get:

$$
\begin{gathered}
Z_{t}=(L+M K L) X_{t}+M(I-K L) X_{t \mid t-1}+(I+M K) v_{t}, \\
i_{t}=(F-F K L) X_{t \mid t-1}+F K L X_{t}+F K v_{t} .
\end{gathered}
$$

Finally, I can rewrite (23) and (24) in state-space form:

$$
f_{t}=C S_{t}+D v_{t}
$$

where $f_{t}^{\prime} \equiv\left[Z_{t}^{\prime} i_{t}\right], C=\left[\begin{array}{cc}L+M K L & M(I-K L) \\ F K L & F(I-K L)\end{array}\right], \quad D=\left[\begin{array}{c}I+M K \\ F K\end{array}\right]$.

adding a vector of measurement errors I get:

$$
f_{t}=C S_{t}+e_{2, t}
$$

where $e_{2, t} \equiv D v_{t}+\xi_{t}$, is the vector of measurement errors and $\xi_{t} \equiv\left[\begin{array}{cccc}0 & 0 & 0 & \xi_{i, t}\end{array}\right]^{\prime}$.

$$
\begin{gathered}
V_{1} \equiv E\left(e_{1, t+1} e_{1, t+1}^{\prime}\right)=\left[\begin{array}{cc}
\Sigma_{u}^{2} & 0 \\
0 & \Sigma_{v}^{2}
\end{array}\right], \\
V_{2} \equiv E\left(e_{2, t} e_{2, t}^{\prime}\right)=D \Sigma_{v}^{2} D^{\prime}+E\left(\xi_{t} \xi_{t}^{\prime}\right), \\
V_{3} \equiv E\left(e_{1, t+1} e_{2, t}^{\prime}\right)=\left[\begin{array}{c}
0 \\
\Sigma_{v}^{2} D^{\prime}
\end{array}\right] .
\end{gathered}
$$

The Kalman filter is then applied to the state space model (18) and (22). The filter takes the observations of $f_{t}$ for $t=1,2, \ldots . T$ and works recursively to construct a series of forecast errors as follows:

$$
w_{t}=f_{t}-f_{t \mid t-1}=f_{t}-C S_{t \mid t-1},
$$

where $f_{t \mid t-1}$ is the prediction of the observable variables given the information available at period $t$ and the forecast error covariance matrix is given by:

$$
\begin{gathered}
\Xi_{t} \equiv E\left(w_{t} w_{t}^{\prime}\right)=E\left(f_{t}-f_{t \mid t-1}\right)\left(f_{t}-f_{t \mid t-1}\right)^{\prime}= \\
=E\left[\left(C S_{t}+e_{2, t}-C S_{t \mid t-1}\right)\left(C S_{t}+e_{2, t}-C S_{t \mid t-1}\right)^{\prime}\right]=
\end{gathered}
$$




$$
\begin{gathered}
=E\left\{\left[C\left(S_{t}-S_{t \mid t-1}\right)+e_{2, t}\right]\left[C\left(S_{t}-S_{t \mid t-1}\right)+e_{2, t}\right]\right\}^{\prime}= \\
=E\left[C\left(\left(S_{t}-S_{t \mid t-1}\right)\left(S_{t}-S_{t \mid t-1}\right)^{\prime} C^{\prime}\right]+E\left(e_{2, t} e_{2, t}^{\prime}\right)=C \Sigma_{t \mid t-1}^{2} C^{\prime}+V_{2},\right.
\end{gathered}
$$

where $\Sigma_{t \mid t-1}^{2}=E\left(S_{t}-S_{t \mid t-1}\right)\left(S_{t}-S_{t \mid t-1}\right)^{\prime}$.

Since by construction, the forecast error $w_{t}$ is serially uncorrelated and normally distributed for all $t=1,2, \ldots, T$ with mean zero and covariance matrix $\Xi_{t}$, then loglikelihood function is given by:

$$
\ln L=-\frac{n T}{2} \log (2 \pi)-\frac{1}{2} \sum_{t=1}^{T} \ln \left|\Xi_{t}\right|-\frac{1}{2} \sum_{t=1}^{T} w_{t} \Xi_{t}^{-1} w_{t}^{\prime} .
$$

The optimal predictor of the states vector using the Kalman filter is given by:

$$
\begin{gathered}
S_{t+1 \mid t}=A S_{t \mid t-1}+K_{t} w_{t} \\
K_{t} \equiv\left(A \Sigma_{t \mid t-1}^{2} C^{\prime}+B V_{3}\right)\left(C \Sigma_{t \mid t-1}^{2} C^{\prime}+V_{2}\right)^{-1}, \\
\Sigma_{t+1 \mid t}^{2}=\left(A \Sigma_{t \mid t-1}^{2} A^{\prime}+B V_{1} B^{\prime}\right)-K_{t}\left(A \Sigma_{t \mid t-1}^{2} C^{\prime}+B V_{3}\right)^{\prime},
\end{gathered}
$$

where the matrix $K_{t}$ is the Kalman gain and $\Sigma_{t+1 \mid t}^{2} \equiv E\left(S_{t+1}-S_{t+1 \mid t}\right)\left(S_{t+1}-S_{t+1 \mid t}\right)^{\prime}$.

\section{Prior Distributions}

The first four columns of Table 1 present prior distributions of the model parameters. For convenience, it is typically assumed that all parameters are a priori independent. Prior distributions are centered around standard calibrated values of the parameters used in the literature while standard errors are chosen in order to cover the range of existing estimates and to avoid to impose too much structure on the data. Since priors are loose, the exact form of the densities is chosen for computational convenience. For the parameters $\alpha, \delta$ and $\rho$ which must lie in the interval $[0,1)$ Beta distributions are chosen. All the variances of shocks are assumed to be distributed as a Gamma distribution because it assures a positive variance with a rather large domain. Gamma distribution is also used for the inflation elasticity to the output gap $\kappa$ in order to include in its domain the wide range of estimated and calibrated parameter values suggested by the literature. The normal distribution is chosen for the remaining parameters. The discount factor $\beta$ is calibrated to be 0.99 . 


\section{References}

[1] Clarida, R., Galí, J., Gertler, M., 1999. The science of monetary policy: A newKeynesian perspective. Journal of Economic Literature 37, 1661-1707.

[2] Cukierman, A., Lippi, F., 2005. Endogenous monetary policy with unobserved potential output. Journal of Economic Dynamics and Control 29, 1951-1983.

[3] Dennis, R., 2006. The policy preferences of the U.S. Federal Reserve. Journal of Applied Econometrics 21, 55-77.

[4] Ehrmann, M., Smets, F., 2003. Uncertain potential output: Implications for monetary policy. Journal of Economic Dynamics and Control 27, 1611-1638.

[5] Fernández-Villaverde, J., Rubio-Ramirez, J., 2004. Comparing dynamic equilibrium models to the data. Journal of Econometrics 123, 153-187.

[6] Galí, J., Gertler M., López-Salido, D., 2005. Robustness of the estimates of the hybrid new Keynesian Phillips curve. Journal of Monetary Economics 52, 1107-1118.

[7] Galí, J., Gertler, M., 1999. Inflation dynamics: A structural econometric analysis. Journal of Monetary Economics 44, 195-222.

[8] Lansing, K., 2000. Learning about the shift in trend output: Implications for monetary policy and inflation. Federal Reserve Bank of San Francisco, Working Paper No. 16.

[9] Lippi, F., Neri, S., 2007. Information variables for monetary policy in an estimated structural model of the Euro Area. Journal of Monetary Economics 54, 1256-1270.

[10] Orphanides, A., 2003. The quest for prosperity without inflation. Journal of Monetary Economics 50, 633-663.

[11] Orphanides, A., 2001. Monetary policy rules based on real-time data. American Economic Review 91 (4), 964-985.

[12] Rotemberg, J., Woodford, M., 1997. An optimization-based econometric framework for the evaluation of monetary policy. NBER Macroeconomics Annual 12, 297-346.

[13] Sargent, T., 1989. Two models of measurement and the investment accelerator. Journal of Political Economy 97, 251-287.

[14] Sbordone, A., 2002. Prices and unit labor costs: A new test of price stickiness. Journal of Monetary Economics 49, 265-292.

[15] Schorfheide, F., 2001. Loss function-based evaluation of DSGE models. Journal of Applied Econometrics 15, 645-670. 
[16] Smets, F., Wouters, R., 2003. An estimated dynamic stochastic general equilibrium model of the Euro Area. Journal of the European Economic Association, 1123-1175.

[17] Svensson, L.E.O., 1997a. Inflation forecast targeting: Implementing and monitoring inflation targets. European Economic Review 41, 1111-1146.

[18] Svensson, L.E.O., 1997b. Optimal inflation targets, 'conservative' central banks, and linear inflation contracts. American Economic Review 87, 98-114.

[19] Svensson, L.E.O., Woodford, M., 2003. Indicator variables for optimal policy. Journal of Monetary Economics 50, 691-720. 


\section{Tables and figures}

Table 1 - Posterior distributions

\begin{tabular}{l|l|cccc}
\hline \hline \multirow{2}{*}{ Name } & \multicolumn{2}{l}{ Prior distributions } & \multicolumn{2}{c}{ Posterior distributions } \\
\cline { 2 - 6 } & Density & Mean & St.dev. & Median & $95 \%$ interval \\
\hline$\alpha$ & Beta & 0.5 & 0.22 & 0.51 & {$[0.43,0.53]$} \\
$\delta$ & Beta & 0.5 & 0.22 & 0.59 & {$[0.59,0.60]$} \\
$\sigma$ & Normal & 0.5 & 0.10 & 0.13 & {$[0.12,0.19]$} \\
$\kappa$ & Gamma & 0.2 & 0.14 & 0.06 & {$[0.03,0.10]$} \\
$\lambda$ & Normal & 0.2 & 0.15 & 0.52 & {$[0.50,0.52]$} \\
$\nu$ & Beta & 0.75 & 0.14 & 0.62 & {$[0.60,0.63]$} \\
$\rho$ & Beta & 0.75 & 0.14 & 0.85 & {$[0.84,0.87]$} \\
$\mu$ & Normal & 1.00 & 0.10 & 1.27 & {$[1.22,1.28]$} \\
$\sigma_{u, \pi}$ & Gamma & 0.002 & 0.001 & 0.54 & {$[0.34,0.64]$} \\
$\sigma_{u, y}$ & Gamma & 0.002 & 0.001 & 0.65 & {$[0.53,0.71]$} \\
$\sigma_{u, \bar{y}}$ & Gamma & 0.002 & 0.001 & 0.39 & {$[0.25,0.47]$} \\
$\sigma_{v, \pi}$ & Gamma & 0.002 & 0.001 & 0.16 & {$[0.15,0.21]$} \\
$\sigma_{v, y}$ & Gamma & 0.002 & 0.001 & 0.20 & {$[0.20,0.21]$} \\
$\sigma_{v, r}$ & Gamma & 0.002 & 0.001 & 0.52 & {$[0.50,0.53]$} \\
$\sigma_{v, c}$ & Gamma & 0.002 & 0.001 & 0.09 & {$[0.09,0.10]$} \\
\hline \hline
\end{tabular}


Table 2 - Forecast error variance decomposition

\begin{tabular}{llrrcccc}
\hline \hline \multirow{2}{*}{$t=1$} & \multicolumn{3}{c}{ Fundamental shocks } & \multicolumn{3}{c}{ Measurement errors } \\
\cline { 2 - 7 } & & \multicolumn{1}{c}{$u_{\bar{y}}$} & \multicolumn{1}{c}{$u_{y}$} & $u_{\pi}$ & $v_{y}$ & $v_{\pi}$ & $v_{c}$ \\
\cline { 2 - 7 } & output & 0.48 & 97.95 & 0.27 & 1.04 & 0.20 & 0.06 \\
& inflation & 0.41 & 2.37 & 95.42 & 0.06 & 1.75 & 0 \\
& int. rate & 6.77 & 49.20 & 37.21 & 1.65 & 4.96 & 0.22 \\
& output gap & 15.71 & 82.96 & 0.23 & 0.88 & 0.17 & 0.05 \\
& int. rate changes & 6.94 & 50.49 & 38.19 & 0.71 & 3.35 & 0.31 \\
& & & & & & & \\
& output & 10.00 & 76.97 & 11.80 & 0.63 & 0.55 & 0.06 \\
& inflation & 0.93 & 5.71 & 92.29 & 0.06 & 1.00 & 0 \\
& int. rate & 6.28 & 53.45 & 38.19 & 0.70 & 1.32 & 0.06 \\
& output gap & 13.72 & 73.78 & 11.31 & 0.60 & 0.53 & 0.06 \\
& int. rate changes & 7.07 & 50.06 & 38.59 & 0.70 & 3.28 & 0.30 \\
& & & & & & \\
& output & 19.61 & 58.65 & 20.72 & 0.48 & 0.50 & 0.04 \\
& inflation & 0.97 & 6.04 & 91.99 & 0.06 & 0.94 & 0 \\
& int. rate & 6.23 & 54.08 & 37.74 & 0.66 & 1.24 & 0.06 \\
& output gap & 11.95 & 64.23 & 22.69 & 0.52 & 0.55 & 0.05 \\
& int. rate changes & 7.18 & 50.34 & 38.78 & 0.64 & 2.81 & 0.25 \\
& & & & & & & \\
& output & 20.78 & 57.71 & 20.50 & 0.47 & 0.49 & 0.04 \\
& inflation & 0.97 & 6.04 & 91.99 & 0.06 & 0.94 & 0 \\
& int. rate & 6.34 & 53.98 & 37.73 & 0.66 & 1.24 & 0.06 \\
& output gap & 11.94 & 64.15 & 22.79 & 0.52 & 0.55 & 0.05 \\
& int. rate changes & 7.2 & 50.31 & 38.79 & 0.64 & 2.80 & 0.25 \\
\hline \hline
\end{tabular}

Table 3 - Targets' standard deviations under different information sets

\begin{tabular}{l|c|c}
\hline \multirow{2}{*}{\multicolumn{1}{c|}{ st.dev. }} & \multicolumn{2}{c}{ Indicators } \\
\cline { 2 - 3 } & all indicators & no unit labor costs \\
\hline output gap & 1.16 & 1.31 \\
inflation & 1.37 & 1.37 \\
interest changes & 1.03 & 1.00 \\
\hline$\%$ increase in expected losses & - & 6.76 \\
\hline \hline
\end{tabular}



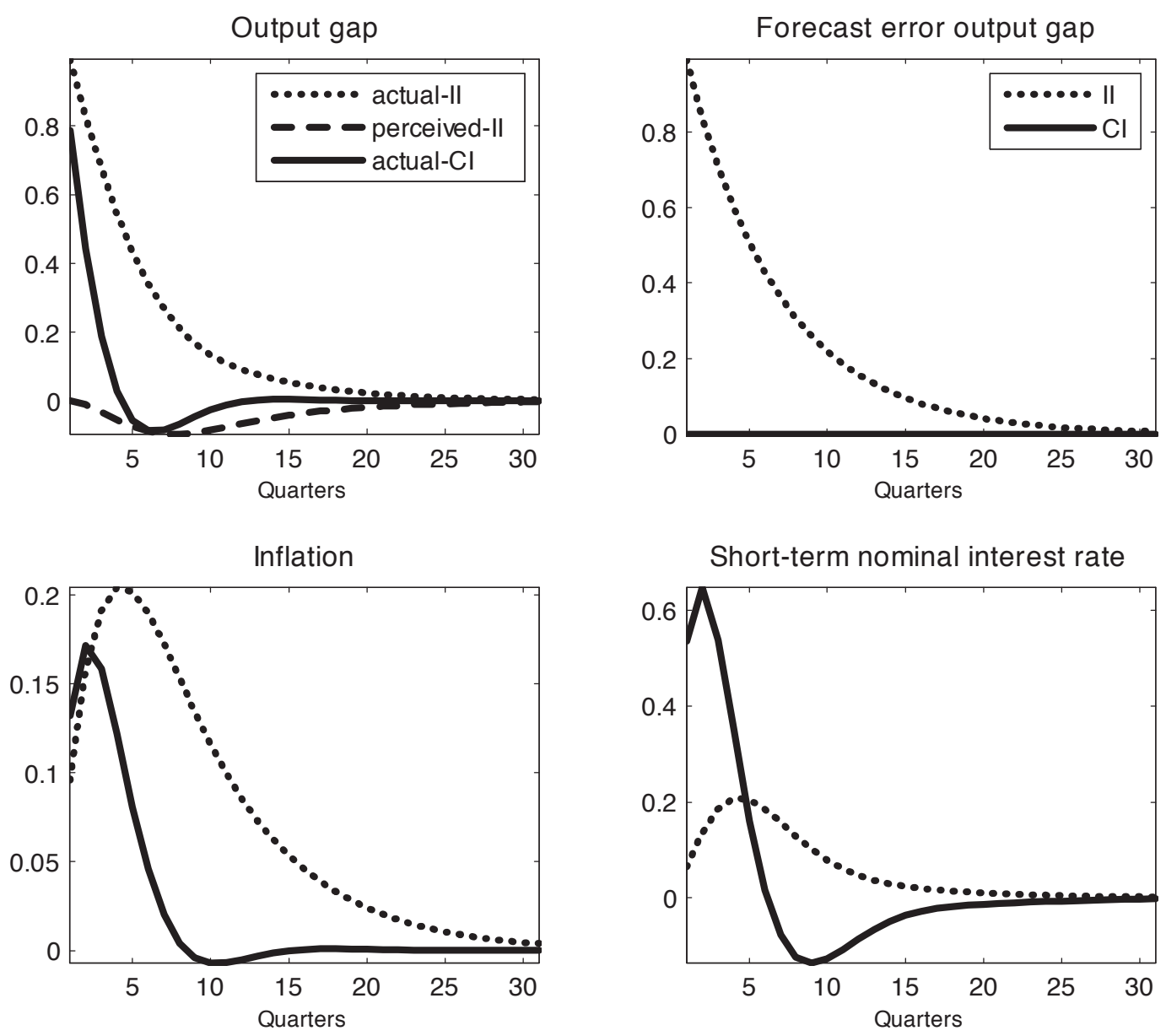

Fig. 1. Responses to a negative potential output shock (real unit labor cost is not available) 

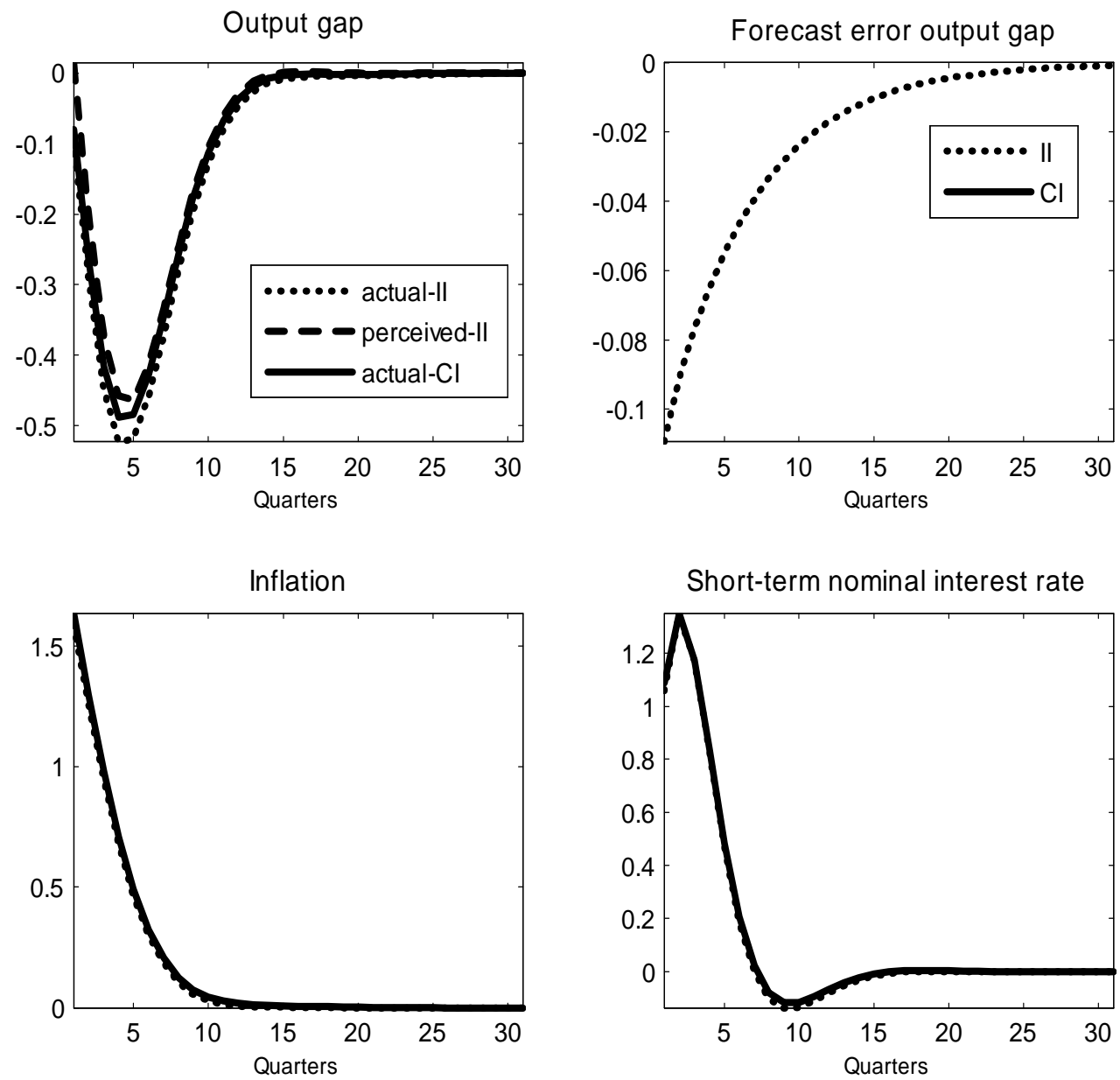

Fig. 2. Responses to a positive cost-push shock (real unit labor cost is not available) 

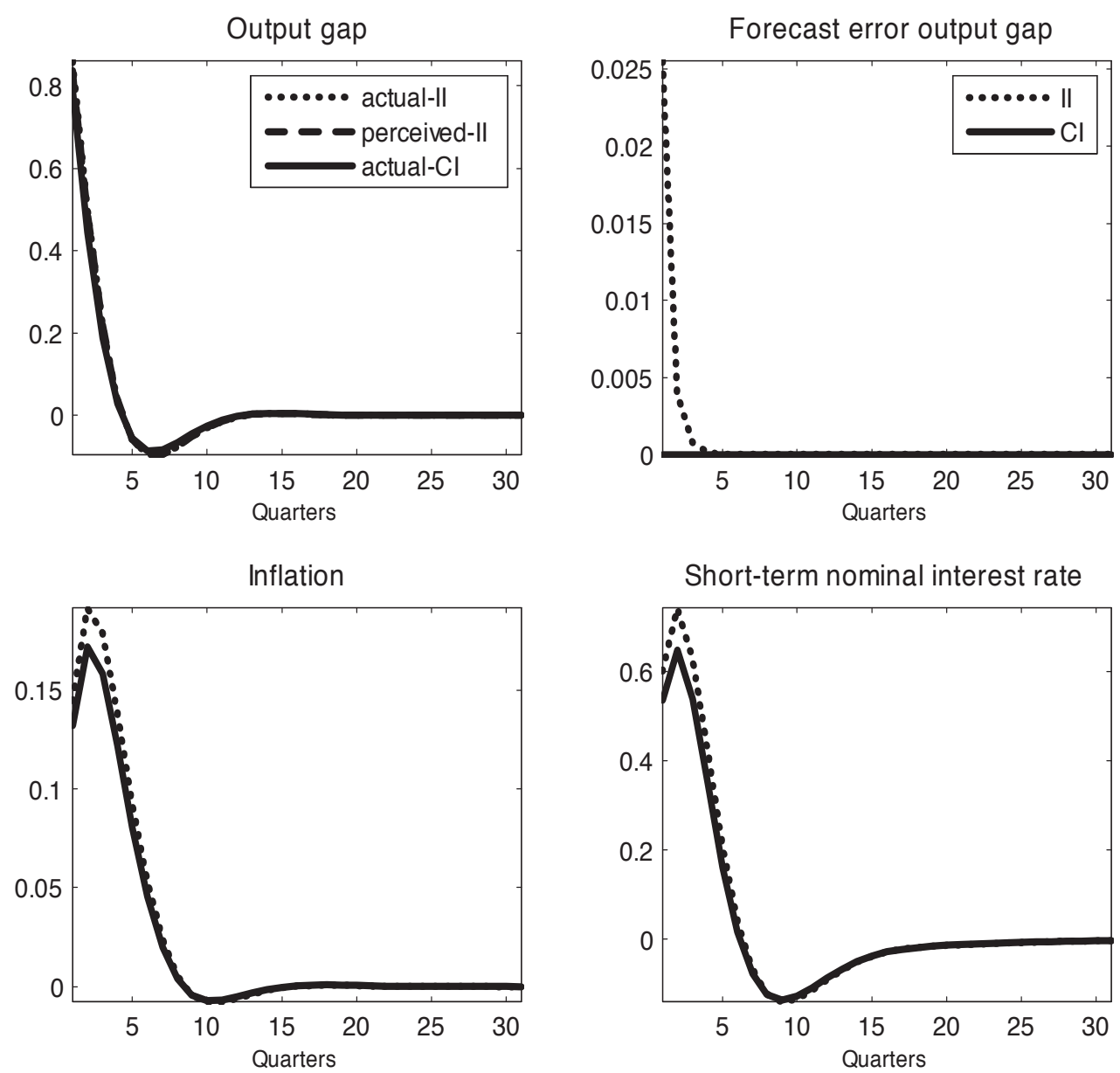

Fig. 3. Responses to a negative potential output shock (real unit labor cost is available) 

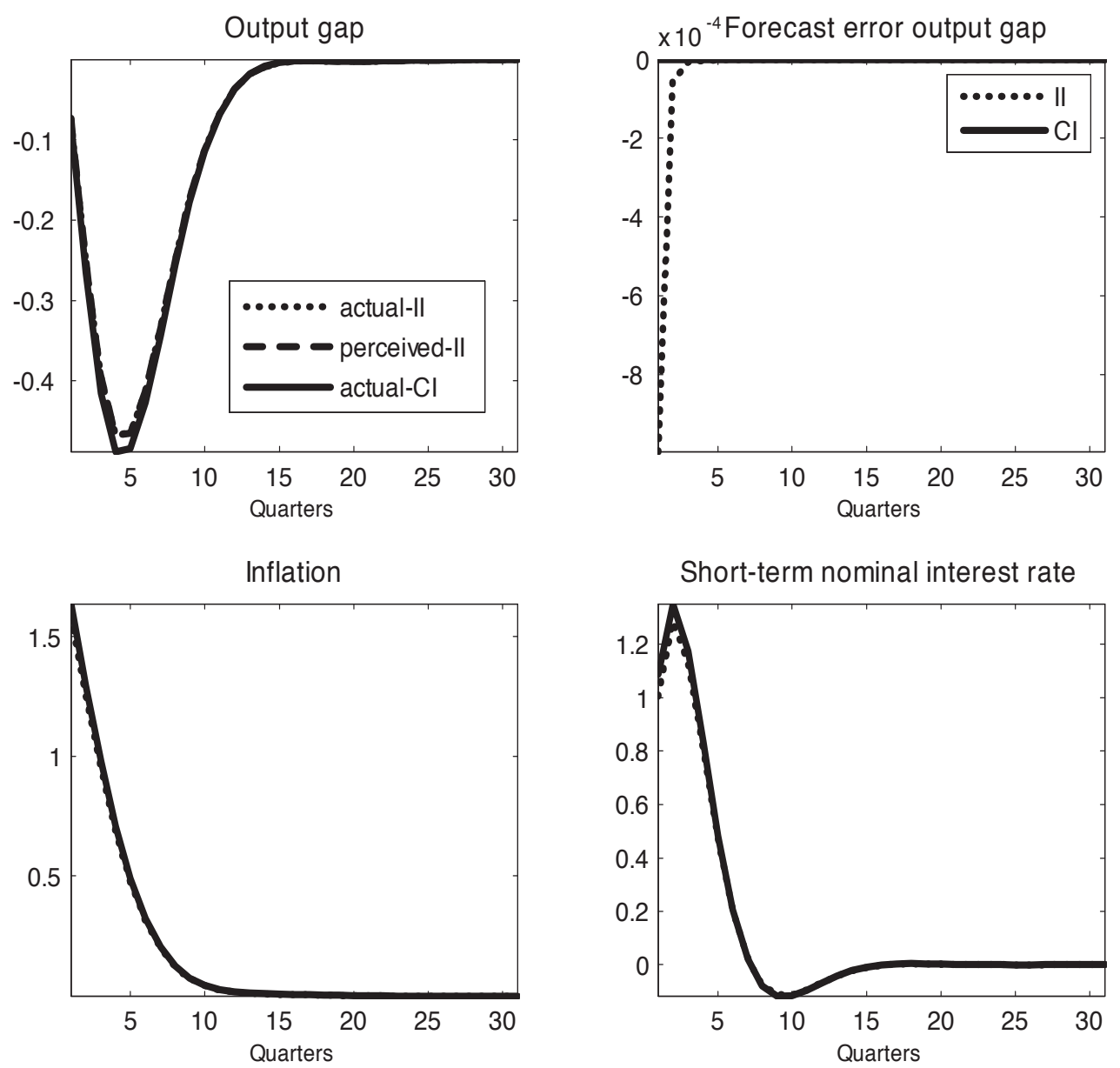

Fig. 4. Responses to a positive cost-push shock (real unit labor cost is available) 


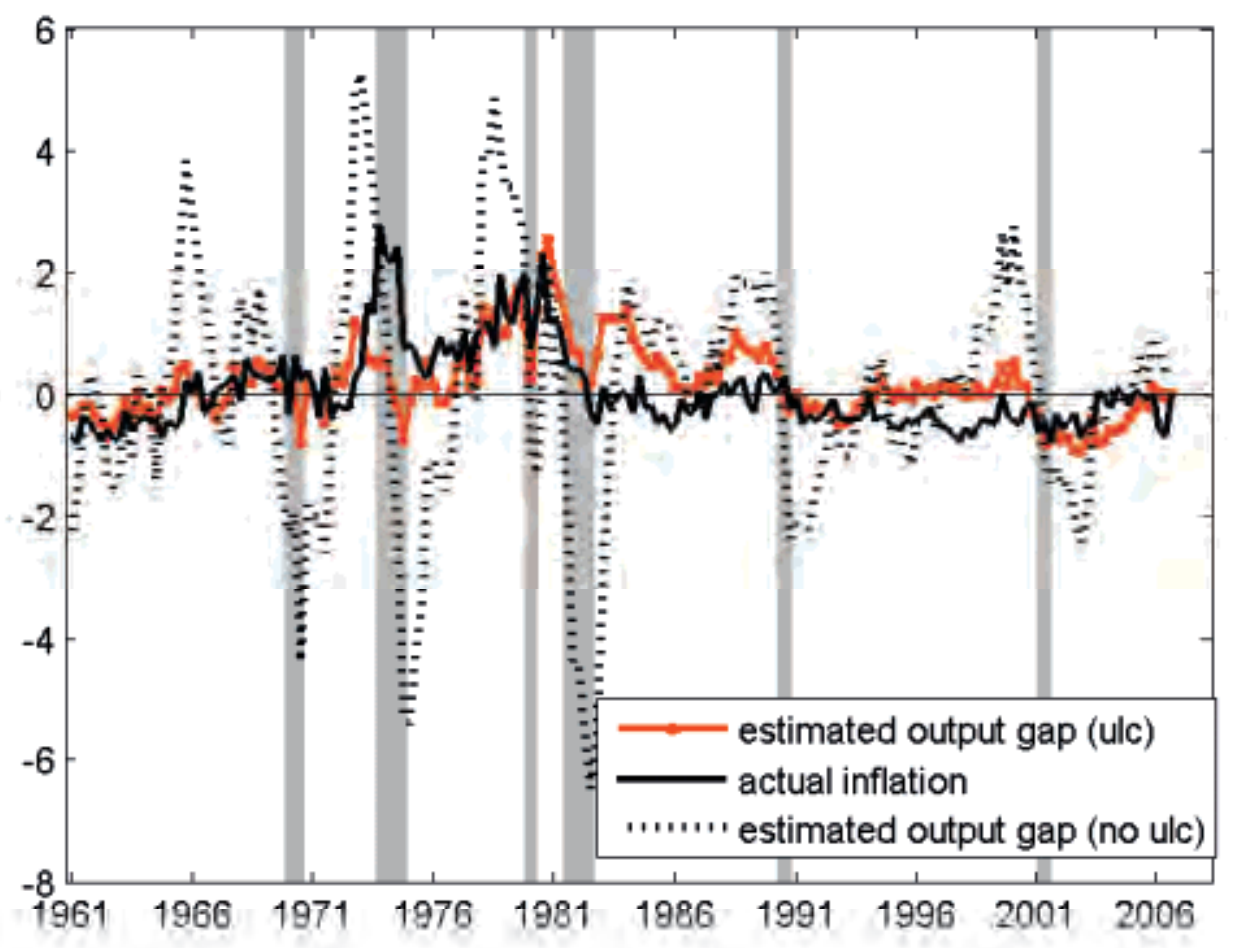

Fig. 5. Actual inflation and two output gap estimates 

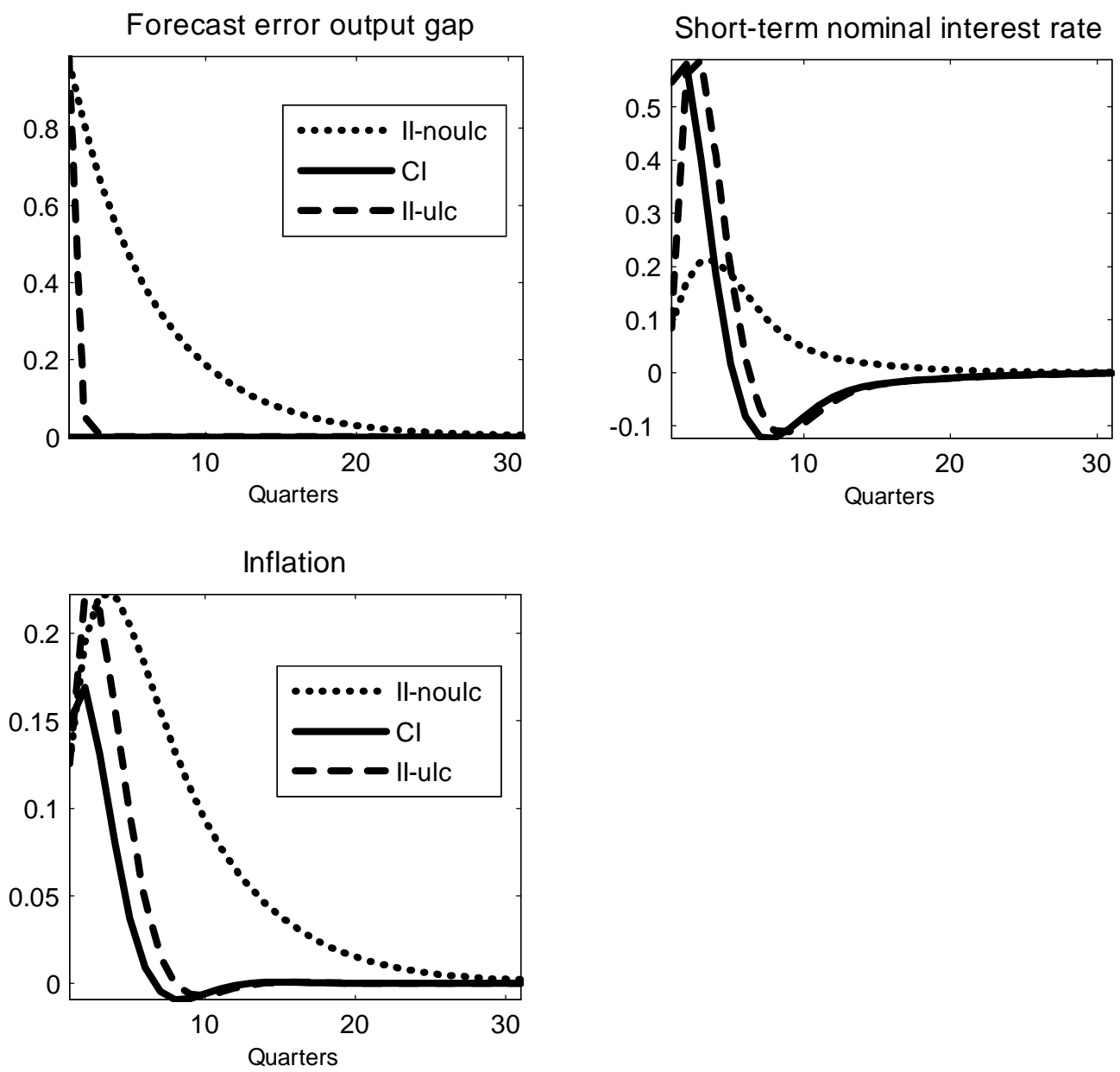

Fig. 6. Responses to a negative potential output shock (real variables are observed with a quarter lag) 


\section{European Central Bank Working Paper Series}

For a complete list of Working Papers published by the ECB, please visit the ECB's website (http://www.ecb.europa.eu).

1086 "Euro area money demand: empirical evidence on the role of equity and labour markets" by G. J. de Bondt, September 2009.

1087 "Modelling global trade flows: results from a GVAR model” by M. Bussière, A. Chudik and G. Sestieri, September 2009.

1088 "Inflation perceptions and expectations in the euro area: the role of news" by C. Badarinza and M. Buchmann, September 2009.

1089 "The effects of monetary policy on unemployment dynamics under model uncertainty: evidence from the US and the euro area" by C. Altavilla and M. Ciccarelli, September 2009.

1090 "New Keynesian versus old Keynesian government spending multipliers" by J. F. Cogan, T. Cwik, J. B. Taylor and V. Wieland, September 2009.

109I "Money talks" by M. Hoerova, C. Monnet and T. Temzelides, September 2009.

1092 "Inflation and output volatility under asymmetric incomplete information" by G. Carboni and M. Ellison, September 2009.

1093 "Determinants of government bond spreads in new EU countries" by I. Alexopoulou, I. Bunda and A. Ferrando, September 2009.

1094 "Signals from housing and lending booms" by I. Bunda and M. Ca'Zorzi, September 2009.

1095 “Memories of high inflation” by M. Ehrmann and P. Tzamourani, September 2009.

1096 "The determinants of bank capital structure" by R. Gropp and F. Heider, September 2009.

1097 "Monetary and fiscal policy aspects of indirect tax changes in a monetary union" by A. Lipińska and L. von Thadden, October 2009.

1098 "Gauging the effectiveness of quantitative forward guidance: evidence from three inflation targeters" by M. Andersson and B. Hofmann, October 2009.

1099 "Public and private sector wages interactions in a general equilibrium model” by G. Fernàndez de Córdoba, J. J. Pérez and J. L. Torres, October 2009.

I 100 "Weak and strong cross section dependence and estimation of large panels" by A. Chudik, M. Hashem Pesaran and E. Tosetti, October 2009.

II0I "Fiscal variables and bond spreads - evidence from eastern European countries and Turkey" by C. Nickel, P. C. Rother and J. C. Rülke, October 2009.

I 102 "Wage-setting behaviour in France: additional evidence from an ad-hoc survey" by J. Montornés and J.-B. Sauner-Leroy, October 2009.

I 103 "Inter-industry wage differentials: how much does rent sharing matter?" by P. Du Caju, F. Rycx and I. Tojerow, October 2009. 
I 104 "Pass-through of external shocks along the pricing chain: a panel estimation approach for the euro area" by B. Landau and F. Skudelny, November 2009.

I 105 "Downward nominal and real wage rigidity: survey evidence from European firms” by J. Babecký, P. Du Caju, T. Kosma, M. Lawless, J. Messina and T. Rõõm, November 2009.

I 106 "The margins of labour cost adjustment: survey evidence from European firms” by J. Babecký, P. Du Caju, T. Kosma, M. Lawless, J. Messina and T. Rõõm, November 2009.

I 107 “Interbank lending, credit risk premia and collateral” by F. Heider and M. Hoerova, November 2009.

I 108 "The role of financial variables in predicting economic activity" by R. Espinoza, F. Fornari and M. J. Lombardi, November 2009.

I 109 “What triggers prolonged inflation regimes? A historical analysis.” by I. Vansteenkiste, November 2009.

I I 10 "Putting the New Keynesian DSGE model to the real-time forecasting test" by M. Kolasa, M. Rubaszek and P. Skrzypczyński, November 2009.

I I I "A stable model for euro area money demand: revisiting the role of wealth" by A. Beyer, November 2009.

I I I 2 "Risk spillover among hedge funds: the role of redemptions and fund failures" by B. Klaus and B. Rzepkowski, November 2009.

II I 3 "Volatility spillovers and contagion from mature to emerging stock markets" by J. Beirne, G. M. Caporale, M. Schulze-Ghattas and N. Spagnolo, November 2009.

I I 4 "Explaining government revenue windfalls and shortfalls: an analysis for selected EU countries" by R. Morris, C. Rodrigues Braz, F. de Castro, S. Jonk, J. Kremer, S. Linehan, M. Rosaria Marino, C. Schalck and O. Tkacevs.

I I I5 "Estimation and forecasting in large datasets with conditionally heteroskedastic dynamic common factors" by L. Alessi, M. Barigozzi and M. Capasso, November 2009.

I I I6 "Sectorial border effects in the European single market: an explanation through industrial concentration" by G. Cafiso, November 2009.

II 17 "What drives personal consumption? The role of housing and financial wealth" by J. Slacalek, November 2009.

I I 8 "Discretionary fiscal policies over the cycle: new evidence based on the ESCB disaggregated approach" by L. Agnello and J. Cimadomo, November 2009.

I I 9 "Nonparametric hybrid Phillips curves based on subjective expectations: estimates for the euro area" by M. Buchmann, December 2009.

I 120 "Exchange rate pass-through in central and eastern European member states" by J. Beirne and M. Bijsterbosch, December 2009.

II 2 I "Does finance bolster superstar companies? Banks, Venture Capital and firm size in local U.S. markets" by A. Popov, December 2009.

I I 22 “Monetary policy shocks and portfolio choice” by M. Fratzscher, C. Saborowski and R. Straub, December 2009.

I I 23 “Monetary policy and the financing of firms" by F. De Fiore, P. Teles and O. Tristani, December 2009.

I I 24 "Balance sheet interlinkages and macro-financial risk analysis in the euro area" by O. Castrén and I. K. Kavonius, December 2009. 
I I 25 “Leading indicators in a globalised world” by F. Fichtner, R. Rüffer and B. Schnatz, December 2009.

I I 26 "Liquidity hoarding and interbank market spreads: the role of counterparty risk" by F. Heider, M. Hoerova and C. Holthausen, December 2009.

I I 27 “The Janus-headed salvation: sovereign and bank credit risk premia during 2008-09” by J. W. Ejsing and W. Lemke, December 2009.

I 128 "EMU and the adjustment to asymmetric shocks: the case of Italy" by G. Amisano, N. Giammarioli and L. Stracca, December 2009.

I 129 "Determinants of inflation and price level differentials across the euro area countries" by M. Andersson, K. Masuch and M. Schiffbauer, December 2009.

I 30 “Monetary policy and potential output uncertainty: a quantitative assessment” by S. Delle Chiaie, December 2009. 
